\title{
Effects of Process Parameters in the Production of High Density Polyethylene-Grass Composite
}

\author{
*OLODU, DD; OSARENMWINDA, JO
}

\author{
Department of Production Engineering, Faculty of Engineering, University of Benin, Benin City, Nigeria \\ *Corresponding Author Email: dickson.olodu@eng.uniben.edu; joosarenmwinda@uniben.edu, Tel: +2348065325363, +2348023718684
}

\begin{abstract}
This study investigates the effects of process parameters in the production of high density polyethylene-grass composite; the process parameters and their interaction on the mechanical properties of the produced high density polyethylene-grass composite were investigated using split-split plot design. The results of the calculated Fisher's Ratio $\left(F_{c a l}\right)$ at significant value of 0.05 for the process parameters such as percentage by volume of material, barrel temperature, material type and their interactions ranges from -80.11 to 29.95 , and were presented on ANOVA Table. The results obtained shows that these process parameters contribute significantly to the production of high density polyethylene-grass composite in polymeric industries.
\end{abstract}

\section{DOI: https://dx.doi.org/10.4314/jasem.v22i9.20}

Copyright: Copyright $\odot 2018$ Olodu and Osarenmwinda. This is an open access article distributed under the Creative Commons Attribution License (CCL), which permits unrestricted use, distribution, and reproduction in any medium, provided the original work is properly cited.

Dates: Received: 28 May 2018; Revised: 27August 2018; Accepted: 17 September 2018

Keywords: High density polyethylene-Grass composite, mechanical properties, Process parameters, Split-Split Plot Design

A qualitative analysis of the influence of process parameters (barrel temperature, type of material and percentage by volume of material) on the mechanical properties of injection moulded high density polyethylene-grass composite will be helpful in gaining better insight into the presently used processing methods (Olodu, 2017). Process parameters and its interaction is a great challenge in the production of high density polyethylene-grass composite. Inadequate investigation of the interaction of some process variables of HDPE-Grass composite had resulted to most failure in the manufacture of these composite. Ranjusha et al (2012) studied the flexural strength of high density polypropylene/clay/glass fibre composites. They obtained a value of $32.25 \times 10^{2}$ $\mathrm{N} / \mathrm{mm}^{2}$ at a barrel temperature of $190^{\circ} \mathrm{C}$. They concluded that the value obtained was probably high due to the presence of clay and glass fibre in the high density polypropylene material. Chunping et al (2007) carried out a study aimed to model fundamental bonding characteristics and performance of wood composite. In their work, mathematical model and a computer simulation model was developed to predict the variation of inter-element contact during mat consolidation. The mathematical predictions and the computer simulations agree well with each other. Their results showed that the relationship between the inter-element contact and the mat density was highly nonlinear and was significantly affected by the wood density and the element thickness. Goos and Vandebroek (2003); Loeza-Serrano and Donev (2014) constructed D-optimal design for variance components estimation in a three stage crossed and nested classification for experiments that includes both crossed and nested factor in the same model, no assumption of a complete random model was made. Moreover, the designed experiment for variance component estimation was based on the linear mixed effect model. Ankenman et al., (2001); Aviles and Pinheiro (2001) examined the experiments that have complete randomization order of runs which was not feasible or might be too expensive to use when performed. They concluded from their study that the use of split-plot designs and models are feasible, efficient and cheap. Split plot designs were initially developed by Fisher in 1925, it was used in agricultural experiments, and it was basically the modified form of randomized block designs. These designs were used in situations where complete randomization of runs within block is not possible. These designs were used widely in industrial experiments such as experiments where one set of factors may require a large amount of experimental materials (Whole Plot factors), while another set of factors might be applied to smaller experimental materials (Sub Plot factors). Olodu (2017) examined the effect of process parameters such as temperature in the production of polypropylene-grass composites 
using split plot experimental design, his results shows that temperature contributes significantly to the production of composites in polymeric industries. This study seeks to produce a new experimental design for the production of high density polyethylene-grass composite in polymeric industries. The focus of this study was therefore to investigate the effects of process parameters in the production of high density polyethylene-grass composite using split-split plot experimental design.

\section{MATERIALS AND METHODS}

Preparation of Grass: The harvested grass was washed and soaked with dilute sodium hydroxide $(\mathrm{NaOH})$ of concentration $0.10 \mathrm{~mol} / \mathrm{dm}^{3}$ for 6 hours to ensure effective bonding between the grass and High Density Polyethylene. The grasses were first air dried in the sun and later transferred to an oven and dried at $105^{\circ} \mathrm{C}$. It was continuously monitored until moisture content of about $4 \pm 0.2 \%$ was obtained (Adeyemi and Adeyemi, 2016). The grass was ground to granules using crushing machine. The ground grass was screened to a particle size of $300 \mu \mathrm{m}$ diameters using vibrating sieve machine.

Production of HDPE-Grass Composites: High Density Polyethylene (HDPE) was mixed with ground grass in the ratio of 20:80, 30:70, 40:60, 50:50, 60:40, 70:30 and 80:20 percentages by volume. The prepared high density polyethylene-grass composite was blended in a cylindrical container until a homogenous mixture was obtained in the composite. The homogenous mixture of the composite was feed into the hopper of injection moulding machine and was produced at various barrel temperature ranging from $150^{\circ} \mathrm{C}$ to $250^{\circ} \mathrm{C}$ (Olodu, 2017).

Evaluation of High Density Polyethylene-Grass Composite for Mechanical Strength: The produced composite was evaluated for mechanical strength (tensile strength, proof stress, percentage elongation and flexural strength) using equation 1 to 4 (Osarenmwinda and Olodu, 2015).

Tensile Strength $=\frac{\text { Maximum Load }}{\text { Original Cross }- \text { Sectional Area }}$

The original cross-sectional area of the specimen is $18.9 \mathrm{~mm}^{2}$.

Proof Stress $=\frac{\text { Force at yield }}{\text { Cross - Sectional Area }}$

The Cross-sectional area of specimen $=18.9 \mathrm{~mm}^{2}$. Hence,
Proof Stress $=\frac{\text { Force at yield }}{18.9} \mathrm{~N} / \mathrm{mm}^{2}$

Percentage $(\%)$ Elongation $=\frac{\text { Extension }}{\text { Gauge Length }} \times 100 \%$

Flexural Strength $(E I)=\frac{P L^{3}}{48 y}$

Where $\mathrm{y}$ is the deflection in $\mathrm{mm}, \mathrm{P}=\mathrm{Load}, \mathrm{L}=$ Length of test specimen

Split-Split Plot Design: The split-split plot design which is an experimental design was the method used to investigate the effects of process parameters and the interaction between material type, percentage by volume of material and barrel temperature on the mechanical properties of the produced composite .In simple terms, a split-split plot experiment is a blocked experiment, where the blocks themselves serve as experimental units for a subset of the factors.

$F$-test: The F-test was used for comparing the factors of the total deviation (using equation 5). The statistical significance was tested by comparing the $\mathrm{F}$ test statistic.

$\mathrm{F}=\frac{\text { Variance between treatments }}{\text { Variance within treatments }}$

$\mathrm{F}=\frac{M S_{\text {Treatments }}}{M S_{\text {Error }}}=\frac{S S_{\text {Treatments } /(I-1)}}{S S_{\text {Error }} /(n T-1)}$

The Interactive Model Developed for HDPE-Grass Composites: The Interactive model developed (equation 6) is depicted as:

$\mathrm{X}_{\mathrm{ijkl}}=\mu+\gamma_{i}+\beta_{j}+\delta_{l}+y_{k}+\gamma \beta_{i j}+\gamma y_{i k}+$
$\beta y_{j k}+\gamma \delta_{i l}+\beta \delta_{j l}+y \delta_{l k}+\gamma \beta y_{i j k}+\gamma \beta \delta_{i j l}+$
$\gamma y \delta_{i k l}+\beta y \delta_{j k l}+\gamma \beta \delta y_{i j k l}+\varepsilon_{\mathrm{ijkl}}$

Where: $\mu=$ Mean response; $\gamma_{I}=$ Block variable (mechanical properties); $\beta_{\mathrm{j}}=$ Block variable (barrel temperature); $\delta_{1}=$ Treatment Variable (percentage by volume of material); $\mathrm{y}_{\mathrm{k}}=$ Treatment Variable (type of material); $\gamma \beta_{\mathrm{ij}}=$ Block interaction (mechanical properties and barrel temperature interaction); $\gamma \mathrm{y}_{\mathrm{ik}}=$ Block and Treatment interaction (mechanical properties and type of material interaction); $\beta y_{j k}=$ Treatment Interaction (barrel temperature and type of material interaction); $\gamma \delta_{\text {il }}=$ Block and Treatment interaction (mechanical properties and percentage by volume of material interaction); $\beta \delta_{\mathrm{jl}}=$ Block and Treatment interaction (barrel temperature and percentage by volume of material interaction); $y \delta_{\mathrm{lk}}=$ Treatment Interaction (percentage by volume of 
material and type of material interaction); $\gamma \beta \mathrm{y}_{\mathrm{ijk}}=$ Block and Treatment interaction (mechanical properties, barrel temperature and type of material interaction); $\gamma \beta \delta_{\mathrm{ijl}}=$ Block and Treatment interaction (mechanical properties, barrel temperature and Percentage by volume of material interaction); $y \gamma \delta_{\mathrm{ikl}}=$ Block and Treatment interaction (mechanical properties, type of material and Percentage by volume of material interaction); $\beta y \delta_{j k l}=$ Block and Treatment interaction (barrel temperature, type of material and Percentage by volume of material interaction); $\gamma \beta \delta y_{\mathrm{ijkl}}=$ Block and Treatment interaction (mechanical properties, barrel temperature, type of material and percentage by volume of material interaction); $\mathrm{X}_{\mathrm{ijkl}}=$ Response Variable; $\varepsilon_{\mathrm{ijkl}}=$ Error term

Hypothesis: The null hypothesis with its alternative were formulated for the HDPE composite as follows:

Null Hypothesis $\left(\mathrm{H}_{\mathrm{o}}\right)$ : The percentage by volume of material, material type, barrel temperature and their interactions contributes significantly to the mechanical properties of the composite produced at $\alpha$-value of 0.05 .

Alternate Hypothesis $\left(\mathrm{H}_{1}\right)$ :The percentage by volume of material, material type, barrel temperature and their interactions does not contributes significantly to the mechanical properties of the composite produced at $\alpha$ value of 0.05 .

\section{RESULTS AND DISCUSSION}

Table 1 shows the effects of barrel temperature on mechanical Properties of HDPE-Grass Composites while Table 2 shows ANOVA result for the effects of process parameters and their interactions on produced HDPE-grass composite.

The investigation of treatment effects of materials $\left(S S_{A}\right)$ and percentage by volume of materials $\left(S S_{B}\right)$; and block effects of mechanical strength $\left(S S_{C}\right)$ and barrel temperature $\left(S S_{D}\right)$ respectively shows that the calculated Fisher's ratio values were less than the Fisher ratio values obtained from the table at $\alpha$-value of 0.05 (Table 2).

The results compared favourably with the results obtained by Goos, and Vandebroek (2003) using Doptimal Split-Plot Designs with given numbers and sizes of whole plots.

The results obtained from this study shows that the experimental data do not furnish enough evidence to reject the null hypothesis $\left(H_{o}\right)$ treatment at $\alpha$-value of
0.05. This shows that the treatment effect and the block effect of process parameters contribute significantly to the mechanical property of the produced HDPE-Grass composite in polymeric industries.

Furthermore, the interaction of the process parameters obtained from treatment and block effects such as Material type and percentage by volume of material Interaction $\left(S S_{A B}\right)$; Material type and Mechanical Strength Interaction $\left(S S_{A C}\right)$; Material type and Temperature Interaction $\left(S S_{A D}\right)$; Percentage by Volume of material and Mechanical Strength Interaction $\left(S S_{B C}\right)$; Percentage by volume of material and Temperature Interaction $\left(S S_{B D}\right)$; Mechanical Strength and Temperature Interaction $\left(S S_{C D}\right)$; Material type, Percentage by volume of material and Temperature Interaction $\left(S S_{A B D}\right)$; Material type, Mechanical strength and Temperature Interaction $\left(S S_{A C D}\right)$; Percentage by volume of material, Mechanical strength and Temperature Interaction $\left(S S_{B C D}\right)$ respectively shows that the calculated Fisher's ratio value is less than the Fisher ratio obtained from the table at $\alpha$-value of 0.05 (Table 2).

The results compared favourably with the results obtained by Goos, and Vandebroek (2003). The experimental data do not furnish enough evidence to reject the null hypothesis $\left(H_{o}\right)$ treatment at $\alpha$-value of 0.05 . This shows that the treatment effect and the block effect interaction of these process parameters contribute significantly to the mechanical property of the produced HDPE-Grass composite in polymeric industries.

Moreover, the interaction of the process parameters obtained from treatment effect such as Examination of Treatment Effect of Material type, Percentage by volume of material, and Mechanical Strength Interaction $\left(S S_{A B C}\right)$ shows that the calculated Fisher's ratio value is more than the Fisher ratio obtained at $\alpha$ value of 0.05 (Table 2).

The results compare favourably with the results obtained by Loeza and Donev (2014). The experimental data furnish enough evidence to reject the null hypothesis $\left(H_{o}\right)$ at $\alpha$-value of 0.05 . This shows that the treatment effect of material type, percentage by volume of material and block effect (mechanical strength) interaction parameters does not contribute significantly to the strength of the composite produced in polymeric industries. 
Table 1: Effects of Barrel Temperature on Mechanical Properties of HDPE-Grass Composite

\begin{tabular}{|c|c|c|c|c|c|c|c|c|c|c|c|c|c|}
\hline & & & & & & & & erat & $\left({ }^{\circ} \mathbf{C}\right)$ & & & & \\
\hline $\begin{array}{l}\text { Mechanical } \\
\text { Property }\end{array}$ & $\begin{array}{l}\text { Percentage } \\
\text { by Volume } \\
\text { of HDPE }\end{array}$ & $\begin{array}{l}\text { Percentage } \\
\text { by Volume } \\
\text { of Grass }\end{array}$ & 150 & 160 & 170 & 180 & 190 & 200 & 210 & 220 & 230 & 240 & 250 \\
\hline Tensile & 80 & 20 & 20.34 & 20.55 & 20.68 & 20.90 & 21.10 & 21.23 & 21.38 & 21.24 & 21.96 & 21.85 & 21.50 \\
\hline Strength & 70 & 30 & 21.22 & 21.43 & 21.56 & 21.79 & 21.96 & 22.10 & 22.26 & 22.11 & 22.81 & 22.74 & 22.42 \\
\hline$\left(\mathrm{N} / \mathrm{mm}^{2}\right)$ & 60 & 40 & 22.34 & 22.55 & 22.68 & 22.90 & 23.06 & 23.18 & 23.34 & 23.19 & 23.90 & 23.81 & 23.45 \\
\hline & 50 & 50 & 23.60 & 23.81 & 23.94 & 24.15 & 24.34 & 24.46 & 24.60 & 24.45 & 25.10 & 25.00 & 24.65 \\
\hline & 40 & 60 & 26.35 & 26.55 & 26.68 & 26.90 & 27.08 & 27.20 & 27.35 & 27.15 & 27.99 & 27.92 & 27.59 \\
\hline & 30 & 70 & 25.34 & 25.54 & 25.66 & 25.88 & 25.98 & 26.08 & 26.24 & 26.10 & 26.82 & 26.70 & 26.34 \\
\hline & 20 & 80 & 24.00 & 24.21 & 24.33 & 24.56 & 24.73 & 24.85 & 24.98 & 24.82 & 25.48 & 25.30 & 24.94 \\
\hline Proof Stress & 80 & 20 & 15.56 & 16.46 & 16.62 & 16.72 & 16.13 & 15.73 & 15.40 & 14.55 & 14.36 & 13.94 & 13.44 \\
\hline$(\mathrm{N} / 1$ & 70 & 30 & 16.80 & 17.70 & 17.86 & 17.96 & 17.35 & 16.96 & 16.62 & 15.77 & 15.58 & 15.10 & 14.60 \\
\hline & 60 & 40 & 19.70 & 20.61 & 20.76 & 20.85 & 20.24 & 19.84 & 19.50 & 18.65 & 18.46 & 17.98 & 17.48 \\
\hline & 50 & 50 & 18.75 & 19.63 & 19.78 & 19.78 & 19.18 & 18.57 & 18.33 & 17.49 & 17.29 & 16.80 & 16.30 \\
\hline & 40 & 60 & 18.45 & 19.34 & 19.48 & 19.59 & 18.95 & 18.54 & 18.20 & 17.36 & 17.16 & 16.76 & 16.26 \\
\hline & 30 & 70 & 18.00 & 18.91 & 19.05 & 19.15 & 18.55 & 18.16 & 17.93 & 17.08 & 16.89 & 16.41 & 15.92 \\
\hline & 20 & 80 & 17.80 & 18.70 & 18.86 & 19.00 & 18.42 & 18.00 & 17.68 & 16.84 & 16.64 & 16.16 & 15.60 \\
\hline Percentage & 80 & 20 & 0.55 & 0.65 & 0.75 & 0.92 & 1.12 & 1.22 & 1.31 & 1.50 & 1.60 & 1.70 & 1.73 \\
\hline Elongation & 70 & 30 & 0.60 & 0.70 & 0.80 & 1.00 & 1.20 & 1.30 & 1.38 & 1.58 & 1.67 & 1.78 & 1.81 \\
\hline$(\%)$ & 60 & 40 & 0.70 & 0.80 & 0.90 & 1.10 & 1.30 & 1.40 & 1.50 & 1.70 & 1.80 & 1.90 & 1.92 \\
\hline & 50 & 50 & 0.50 & 0.60 & 0.70 & 0.90 & 1.10 & 1.20 & 1.30 & 1.50 & 1.60 & 1.70 & 1.71 \\
\hline & 40 & 60 & 0.45 & 0.55 & 0.65 & 0.84 & 1.05 & 1.15 & 1.25 & 1.45 & 1.55 & 1.64 & 1.65 \\
\hline & 30 & 70 & 0.40 & 0.50 & 0.62 & 0.80 & 1.00 & 1.10 & 1.20 & 1.40 & 1.50 & 1.60 & 1.62 \\
\hline & 20 & 80 & 0.36 & 0.46 & 0.56 & 0.74 & 0.96 & 1.05 & 1.15 & 1.35 & 1.45 & 1.54 & 1.56 \\
\hline Average & 80 & 20 & 5.10 & 5.06 & 5.11 & 5.16 & 5.19 & 5.20 & 5.23 & 5.24 & 5.25 & 5.24 & 5.21 \\
\hline Deflection & 70 & 30 & 5.25 & 5.21 & 5.27 & 5.32 & 5.35 & 5.36 & 5.39 & 5.41 & 5.42 & 5.41 & 5.37 \\
\hline$(\%)$ & 60 & 40 & 4.83 & 4.91 & 4.96 & 5.00 & 5.02 & 5.03 & 5.06 & 5.07 & 5.08 & 5.07 & 5.03 \\
\hline & 50 & 50 & 5.38 & 5.34 & 5.39 & 5.44 & 5.48 & 5.49 & 5.52 & 5.54 & 5.56 & 5.55 & 5.50 \\
\hline & 40 & 60 & 5.44 & 5.39 & 5.45 & 5.50 & 5.53 & 5.55 & 5.58 & 5.60 & 5.61 & 5.60 & 5.56 \\
\hline & 30 & 70 & 5.68 & 5.63 & 5.69 & 5.74 & 5.77 & 5.79 & 5.82 & 5.84 & 5.86 & 5.84 & 5.80 \\
\hline & 20 & 80 & 5.77 & 5.72 & 5.79 & 5.84 & 5.90 & 5.91 & 5.96 & 5.97 & 5.99 & 5.98 & 6.02 \\
\hline Flexural & 80 & 20 & 40.10 & 40.40 & 40.00 & 39.65 & 39.41 & 39.31 & 39.11 & 39.00 & 38.91 & 38.98 & 39.26 \\
\hline Strength & 70 & 30 & 38.90 & 39.20 & 38.81 & 38.45 & 38.22 & 38.12 & 37.90 & 37.80 & 37.70 & 37.78 & 38.04 \\
\hline $\mathrm{X} 10^{3}\left(\mathrm{~N} / \mathrm{mm}^{2}\right)$ & 60 & 40 & 42.35 & 41.66 & 41.25 & 40.90 & 40.72 & 40.63 & 40.42 & 40.32 & 40.20 & 40.29 & 40.60 \\
\hline & 50 & 50 & 38.00 & 38.30 & 37.90 & 37.55 & 37.32 & 37.21 & 37.00 & 36.88 & 36.78 & 36.85 & 37.18 \\
\hline & 40 & 60 & 37.60 & 37.90 & 37.50 & 37.15 & 36.93 & 36.82 & 36.60 & 36.50 & 36.41 & 36.48 & 36.78 \\
\hline & 30 & 70 & 36.00 & 36.31 & 35.91 & 35.60 & 35.40 & 35.30 & 35.10 & 35.00 & 34.90 & 34.97 & 35.25 \\
\hline & 20 & 80 & 35.40 & 35.71 & 35.31 & 35.00 & 34.62 & 34.52 & 34.32 & 34.21 & 34.11 & 34.18 & 33.98 \\
\hline
\end{tabular}

Table 2: ANOVA Table for the Effects of Process Parameters and their Interactions on the Produced HDPE-Grass Composite

\begin{tabular}{clllll}
\hline $\begin{array}{c}\text { Sources of } \\
\text { Variation }\end{array}$ & $\begin{array}{l}\text { Sum of } \\
\text { Squares (SS) }\end{array}$ & Degree of freedom & $\begin{array}{l}\text { Mean of } \\
\text { Squares (MS) }\end{array}$ & $\begin{array}{l}\text { Fisher's Ratio } \\
\mathbf{F}_{\text {cal }} \mathbf{\alpha = 0 . 0 5}\end{array}$ & $\begin{array}{l}\text { Fisher's } \\
\text { Ratio } \mathbf{F}_{\text {Table }}\end{array}$ \\
\hline$S S_{A}$ & 0.00 & $\mathrm{~K}-1=1$ & 0.00 & 0.00 & 5.99 \\
$S S_{B}$ & 161.35 & $\mathrm{~L}-1=6$ & 26.39 & 0.00 & 4.28 \\
$S S_{C}$ & 105622.38 & $\mathrm{I}-1=3$ & 35207.46 & 0.00 & 9.28 \\
$S S_{D}$ & 24.13 & $\mathrm{~J}-1=10$ & 2.41 & 0.00 & 2.98 \\
$S S_{A B}$ & 0.00 & $(\mathrm{~K}-1)(\mathrm{L}-1)=6$ & 0.00 & 0.00 & 8.94 \\
$S S_{A C}$ & 0.00 & $(\mathrm{~K}-1)(\mathrm{I}-1)=3$ & 0.00 & 0.00 & 3.16 \\
$S S_{A D}$ & -0.00 & $(\mathrm{~K}-1)(\mathrm{J}-1)=10$ & 0.00 & 0.00 & 1.99 \\
$S S_{B C}$ & 1299.40 & $(\mathrm{~L}-1)(\mathrm{I}-1)=18$ & 72.19 & 1.00 & 2.01 \\
$S S_{B D}$ & 0.70 & $(\mathrm{~L}-1)(\mathrm{J}-1)=60$ & 0.01 & 1.00 & 0.51 \\
$S S_{C D}$ & 261.38 & $(\mathrm{I}-1)(\mathrm{J}-1)=30$ & 8.71 & 0.00 & 1.37 \\
$S S_{A B C}$ & 1299.40 & $(\mathrm{~K}-1)(\mathrm{L}-1)(\mathrm{I}-1)=18$ & 72.19 & 29.95 & 2.98 \\
$S S_{A B D}$ & 0.70 & (K-1)(L-1)(I-1)=60 & 0.01 & 0.001 & 0.17 \\
$S S_{A C D}$ & 0.00 & (K-1)(I-1)(J-1)=30 & 0.00 & 0.00 & 1.93 \\
$S S_{B C D}$ & 103965.01 & $(\mathrm{~L}-1)(\mathrm{I}-1)(\mathrm{J}-1)=180$ & 577.58 & -80.11 & \\
$S S_{E}$ & -1297.53 & (I-1)(J-1)(K-1)(L-1)=180 & -7.21 & & \\
$S S_{T}$ & 107371.21 & $\mathrm{IJKL}-1=615$ & & & \\
\hline
\end{tabular}

Conclusion: The results obtained from the interactive model developed using the split-split plot design indicates that there were strong interaction between the barrel temperatures, type of material and percentage by volume of material on mechanical properties (Tensile Strength, Proof Stress, Percentage Elongation and Flexural Strength) for the produced HDPE-Grass composites. Hence, these process parameters contributes significantly to the produced injection moulded HDPE-Grass composite. Decisions 
made based on the hypothesis statements shows that there were no enough evidence to reject the null hypothesis at $\alpha$-value of 0.05 for HDPE-Grass composite.

\section{REFERENCES}

Adeyemi, SO; Adeyemi, MB (2016). Temperature Effect on Extrusion Moulded Plastic. International Journal of Materials and Product Technology. 5 (6): 300-311.

Ankenman, BE; Liu, H; Karr, AF; Picka, JD (2001). A Class of Experimental Designs for Estimating a Response Surface and Variance Components. Journal of Technometrics. 44: 45-54.

Avilles, AI; Pinheiro, JC (2015). Optimal Design for Mixed Effects Models with two Random Nested Factors. Journal of Statistical Sinica. 13: 385401.

Chunping, D; Changing. Y; Cheng, Z (2007). Theoretical Modeling of Bonding Characteristics and Performance of Wood Composites of Inter-element Contact. Journal of Wood and Fiber Science, 39: 48-55.
Goos, P; Vandebroek, M (2003). D-optimal Split-Plot Designs with Given Numbers and Sizes of

Whole Plots. Journal of Technometrics. 45: 235245.

Loeza, S; Donev, AN (2014). Construction of Experimental Design to estimate Variance Components. Journal of Computational Statistics and Data Analysis. 71: 1168-1177.

Osaremwinda, JO; Olodu, DD (2015). Effects of Barrel Temperature on the Mechanical Properties of Injection Moulded Product. Nigeria Journal of Technology (NIJOTECH). 34 (2): 292-296.

Olodu, DD. (2017). Modelling and Development of Injection Moulded Plastic-Grass Composites. PhD Thesis, Department of Production Engineering, Faculty of Engineering, University of Benin, Nigeria.

Ranjusha, JP; Anjana, R; George, KE (2012). Effects of Moulding Temperature on the Properties of High density Polypropylene /Clay/Glass Fibre Composites. International Journal of Engineering and Applications. .2 (5) 922-926. 